\title{
THE TREATMENT OF LEPROSY WITH THIOSEMICARBAZONE
}

\author{
C. W. J. MORRIS, M.D.
}

The thiosemicarbazones (e.g. $\mathrm{TB}_{1}$, conteben, thiacetazone, neustab, berculon A., etc.) have now been used fairly extensively in the treatment of various forms of tuberculosis and leprosy.

A number of workers have reported the results obtained in the treatment of leprosy. Keil(1) reported the work of several groups who have used conteben $\left(\mathrm{TB}_{1}\right)$ with satisfactory results in patients with lepromatous leprosy. Ryrie(2) used the drug in patients with advanced lepromatous disease and lepromatous disease of long standing and found it effective. Schujman (3) described favourable results obtained by Schneider in fourteen lepromatous cases treated for nine months. In his own personal experience he described trials with the drug in fourteen patients, twelve of whom were suffering from the lepromatous type of disease. He reported that the drug was well tolerated, few patients had lepra reactions and the results obtained were very satisfactory as judged by the clinical improvement.

Cochrane(4) does not believe the thiosemicarbazones are as 
effective as the sulphones but should be used as a second line of attack. Lowe ${ }^{(5)}$ treated several large groups with the drug, with satisfactory results. However, in one group of one hundred and forty-six patients treated for a period up to twenty-one months, he reported three cases of acute agranulocytosis. These, however, occurred during the first few weeks of treatment, all between the third and sixth week, and all recovered. A fourth patient with mild agranulocytosis, after recovery, continued with the same treatment, and with no sign of a recurrence of the agranulocytosis. He believes that agranulocytosis appears early or not at all and that his findings support the idea that this agranulocytosis is an allergic rather than a toxic action of the drug.

At the Oyi River Leprosarium in West Kabba Province, Nigeria, patients have been treated with sulphones since I949. Some were first treated with diasone, then sulphetrone, and finally all were put on diamino-diphenylsulphone. During I95I quite a number of the patients were found to be unable to tolerate DDS in the higher doses. A few were found who developed severe allergic reaction to the drug. A small number developed psychotic symptoms which usually cleared up in time on cessation of the drug.

In 1952 there were about twenty-two patients of the one thousand under treatment in the Oyi River Leprosarium (West Kabba Provincial) who were unable to tolerate DDS. It was decided to try them on thiosemicarbazone. In addition to most of these, twenty new admissions-unselected consecutive caseswere added to this group in order to determine if the drug could be used generally without elaborate controls. These new patients were taken as they came, regardless of sex, type, or stage of the disease. They were added to the general group if their haemoglobin was $70 \%$ or over and their general condition was satisfactory.

The thirty-eight patients who were then put on thiosemicarbazone consisted of two groups; one group A, composed of eighteen patients who had previously received treatment with hydnocarpus oil and DDS, while the other group B of twenty included those who had received no previous treatment under medical supervision. (Some and perhaps all may have had some form of native remedy prior to admission.) Others were put on neustab later but these are not included in the group of thirty-eight.

Before starting the drug, all the patients were examined clinically and bacteriologically, the haemoglobin was estimated, and the usual laboratory examinations of stool and urine were carried out.

The drug used was " Neustab " brand of thiacetazone, which is 
para-acetylaminobenzaldehyde thiosemicarbazone. It is packaged in tablets of $25 \mathrm{mg}$. for oral administration. For use in this group of patients, it was supplied without charge by Boots Pure Drug Co., Ltd.

In spite of the probable truth that "agranulocytosis is an allergic rather than a toxic action of the drug," it was felt advisable to proceed with caution. Patients were started on $12.5 \mathrm{mg}$. or 25 $\mathrm{mg}$. and increased slowly up to a total daily dose of $150 \mathrm{mg}$. In most cases the dose of the drug was increased by $25 \mathrm{mg}$. at intervals of roughly three weeks. The patients were given the total dose at one time (the evening) on six days of the week.

Treatment was commenced in June, I952, but doses were reduced in amount in August due to short supply and during October treatment with neustab had to be suspended, due to lack of tablets. During this period patients received only ferrous sulphate tablets grs. iii, thrice daily. From November I, I952, neustab was given regularly up to July 3I, I953. The thirty-eight patients were thus on continuous treatment with neustab for a period of nine months with the exception of one female patient (No. 47I), who left the leprosarium in January.

Of the total of thirty-eight patients, twenty had lepromatous leprosy, ten of these being in group A and ten in Group B. The remainder included tuberculoid, simple macular, and indeterminate cases.

Four of the patients in Group A had developed psychotic symptoms while on DDS, at least one of them having had a preexisting psychotic background. Three in the same group had developed severe repeated lepra reactions on DDS and most of the remainder were allergic to the drug.

\section{Effectiveness of Treatment with "Neustab"}

Clinically, all the patients have shown various degrees of improvement, nineteen being markedly improved, thirteen moderately improved and five slightly improved.

All the patients with lepromatous disease and positive bacteriological findings have shown both clinical and bacteriological improvement.

While only one patient with lepromatous disease, (No. I284), strongly positive at the beginning, has become bacteriologically negative, routine examination of skin and nasal smears showed evidence of a diminution in the numbers of bacilli in the other positive cases. No bacteriological index was done since it was desired to keep the laboratory work at a minimum. 
Patients who developed psychotic symptoms on DDS have shown no evidence of a recurrence on full doses of neustab over a period of six months.

One patient, (No. II94), who had pulmonary tuberculosis with associated chronic productive cough and sputum positive on direct smear, did exceptionally well. During treatment he frequently had an elevation of temperature, between $99^{\circ}$ and $100^{\circ}$, but treatment was continued. Most of his signs and symptoms of leprosy have disappeared, his cough has greatly diminished, and the sputum is now negative for mycobacterium tuberculosis.

\section{Complications}

Relatively few severe complications arose, and the drug was, in most instances, well tolerated.

Fourteen patients had mild lepra reactions while under treatment but in every case showed considerable improvement following the reaction. In some of these the drug was continued throughout the reaction.

One patient, (No. I706), had two mild lepra reactions and one patient, (No. I705), an adult male with far advanced lepromatous disease, had an acute lepra reaction and was unable to resume treatment for three months.

One elderly female patient, (No. I284), with the marked tubero-nodular form of the lepromatous type and strongly positive bacteriologically, had two moderately severe lepra reactions. She is now much improved clinically and is bacteriologically negative.

As with diaminodiphenylsulphone and other drugs, during treatment there was a fairly uniform fall in the haemoglobin level. By giving two tablets (grs. vi) of ferrous sulphate daily, the haemoglobin could be maintained at a suitable level and the patient's condition improved.

\section{Discussion}

These trials were in no sense a " controlled " experiment. A minimum of laboratory work was done. While the number of patients is very small, all showed improvement clinically and no serious complications occurred. In the group of patients who previously had treatment with DDS but were unable to tolerate the drug, neustab gave satisfactory results. A second arrow for the pharmaceutical bow in the battle against leprosy is indeed acceptable and welcome.

\section{SUMMARY}

Thirty-eight patients, twenty having lepromatous leprosy, were 
treated for nine months to one year with neustab. Of the thirtyeight patients, eighteen had had previous treatment with hydnocarpus oil and DDS.

Very few complications occurred during treatment.

All patients showed evidence of clinical improvement and one lepromatous case previously bacteriologically positive became bacteriologically negative.

\section{REFERENCES}

1. KeIL, E. The treatment of leprosy with conteben. Internas. J. Leprosy 19 (1951) 437-444.

2. RYRIE, G. Thiosemicarbazone in the treatment of leprosy. Lancet 2 (1950) 286-287.

3. Schujman, S. Results of one year's experience with TB-1 in the treatment of leprosy. Internat. J. Leprosy 20 (1952) 31-37.

4. Cochrane, R. G. Chemotherapy of leprosy. British Medical Journal 2 (1952) 1220-1223.

5. Lowe, JoHN. Acute agranulocytosis caused by TB 1/698 (Para-Acetamidobenzaldehyde thiosemicarbazone) Leprosy Review 23 (1952) 109-114.

\section{ACKNOWLEDGMENT}

We wish to express our thanks to Boots Pure Drug Company and their local representatives for the supply of " Neustab " to carry out these trials. 